\section{EL DEBATE ACADÉMICO SOBRE NACIÓN Y NACIONALISMO DESDE LOS ORÍGENES HASTA LA CONSOLIDACIÓN DEL PREDOMINIO ANGLOSAJÓN}

\author{
Raúl Moreno Almendral \\ Universidad de Salamanca \\ ramoal@usal.es / raulmorenoalmendral@gmail.com
}

\section{ACADEMIC DEBATES ON NATIONS AND NATIONALISM FROM THE ORIGINS TO THE CONSOLIDATION OF ANGLO- SAXON HEGEMONY}

Cómo citar este artículo/Citation: Moreno Almendral, R. (2015). "El debate académico sobre nación y nacionalismo desde los orígenes hasta la consolidación del predominio anglosajón". Arbor, 191 (775): a272. doi: http://dx.doi. org/10.3989/arbor.2015.775n5011

Recibido: 30 septiembre 2014. Aceptado: 26 marzo 2015.
RESUMEN: El artículo ofrece un recorrido introductorio por las principales aportaciones al debate académico sobre naciones y nacionalismo, desde los primeros intelectuales que abordaron el tema desde una pretensión mínimamente analítica hasta finales del siglo XX, cuando los estudios sobre nación y nacionalismo se consolidaron como un campo específico bajo la hegemonía de las obras escritas en inglés. Considera tanto las primeras aportaciones indirectas de pensadores influyentes como las producciones específicas posteriores de historiadores y científicos sociales sobre el tema y permite reconstruir la trayectoria, larga y diversa, que estos estudios han tenido hasta alcanzar una posición destacada a principios del siglo XXI.

PALABRAS CLAVE: nacionalismo; identidad nacional; historiografía; teoría del nacionalismo.
Copyright: @ 2015 CSIC. Este es un artículo de acceso abierto distribuido bajo los términos de la licencia Creative Commons Attribution-Non Commercial (by-nc) Spain 3.0.
ABSTRACT: This article offers an introductory review of the main contributions to the academic debate about nations and nationalism, from the first intellectuals who addressed the topic with minimally analytical aspirations, down to the late 20th century, when studies of nations and nationalism became established as a specific field under the hegemony of works written in English. It considers both the first indirect contributions by influential thinkers and the later specific output of historians and social scientists on the topic and permits a reconstruction of the long and diverse trajectory that these studies have gone through until reaching an outstanding position in the early 21 st century.

KEYWORDS: nationalism; national identity; historiography; theory of nationalism. 


\section{INTRODUCCIÓN}

El debate académico sobre nación y nacionalismo ha alcanzado en la actualidad unos niveles de densidad y de abundancia de obras muy elevados, a veces difíciles de seguir. Desde los años 90 del siglo XX, las producciones académicas de historiadores, politólogos, sociólogos, antropólogos y demás científicos sociales sobre la teoría y el desarrollo general de los fenómenos nacionales se han incrementado exponencialmente. Sin embargo, el recorrido que ha conducido al momento actual no es tan conocido, más allá de una breve nómina de autores que se suelen tener en mente. El objetivo de este artículo es reconstruir en un espacio reducido la historia de este debate a través de las principales aportaciones que han mediado entre las primeras reflexiones intelectuales sobre la nación en el mundo occidental y la consolidación de los estudios sobre nación y nacionalismo en los años 80-90 del siglo XX. ${ }^{1}$

La estructura cronológica y la selección de autores y contenidos es, por supuesto, personal y debatible. Sin embargo, creemos que proporciona una forma rápida y clara de articular una materia sumamente fragmentada y extensa. En la primera parte, nos apoyamos en algunas de las síntesis disponibles para introducir algunas de las primeras reflexiones sobre la nación que encontramos en los siglos XVIII y XIX, seguidas de las primeras aportaciones a lo que podríamos calificar de debate académico en sentido estricto. En la segunda, se tratan los autores que ayudaron a consolidar el debate y el proceso de adquisición de la hegemonía anglosajona, completado a finales del siglo XX. ${ }^{2}$

Huelga decir que todas estas consideraciones se centran en la esfera de la intelectualidad y de los investigadores. Las esferas públicas en un sentido más abierto y la acción política tanto durante el siglo XIX como el XX estaban impregnadas de referentes nacionales, naturalizaciones de la nación que sobrevivieron a la derrota del fascismo y a la descolonización y que podemos encontrar en el debate público y la conversación cotidiana. Así, la capacidad del entorno y del contexto para influir en el contenido de las diferentes aportaciones tampoco debe subestimarse, aunque proclamen explícitamente haberse desembarazado del nacionalismo metodológico. ${ }^{3}$

\section{AUTORES CLÁSICOS E INICIOS DEL DEBATE ACADÉMICO}

En la actualidad hay algo parecido a un consenso (no completo) en que los primeros que aislaron la nación como concepto cognitivamente analizable fueron los intelectuales, primero ilustrados y luego románticos, que en los siglos XVIII y XIX contribuyeron a la creación de las realidades nacionales, las cuales, por supuesto, eran para la mayoría de ellos incuestionables.

Creemos que hay muy poco margen de duda en que los estudios sobre nación y nacionalismo que tenemos hoy provienen de una reacción antiesencialista que difícilmente se habría producido si la nación no se hubiera convertido previamente en un objeto de exaltación literaria, un elemento fundamental de ciertas cosmovisiones intelectuales o una bandera de enganche para la movilización política.

De hecho, algunas de las aportaciones de estos intelectuales, por muy nacionalistas, poco sistemáticas y/o tangenciales en su pensamiento que fueran, son esenciales para entender la evolución tanto de los movimientos nacionales y los procesos de construcción nacional a lo largo del tiempo como de todos aquellos que acabaron intentando estudiarlos con espíritu analítico.

A modo de síntesis, Özkirimli (2000/2010, pp. 10-16) señala el papel clave de cuatro grandes pensadores, dos ilustrados y dos románticos, en la introducción posterior de la nación en el mundo de la alta cultura como objeto de reflexión. Por un lado, las ideas kantianas del imperativo categórico y de la "voluntad autónoma" como la mejor y más legítima de todas, así como las ideas rousseaunianas de la "voluntad general" y "espíritu de cuerpo" (esprit de corps) que debían dar cohesión a una sociedad e impulsar el sacrificio de sus ciudadanos por el bien común. Por otro lado, la exaltación de Herder hacia un mundo de naciones únicas e inconmensurables, marcadas por la existencia de una lengua portadora de un Volksgeist o espíritu popular particular. Antitética al universalismo de la Ilustración, esta concepción romántica amante del esencialismo y la particularidad fue desarrollada por Fichte, filósofo idealista, quien en sus famosos Reden an die deutsche Nation (1807-1808) profundizó en la que acabaría siendo la típica idea nacionalista de nación, un ente comunitario superior a los individuos y portador de una profunda cultura marcada por unas "características nacionales" (en las cuales los alemanes ocupaban por supuesto el primer puesto en la escala). Aunque no fuera exactamente el contenido de sus discursos, Fichte contribuyó a una idea de la nación como realidad supraindividual, esencial, inmutable y cuasimetafísica que se consolidaría durante todo el siglo XIX.

Contrastando con lo anterior, muchas veces se señala como el primer intento destacable de definir la 
nación desde una pretensión medianamente despegada de la pasión nacionalista la visión de ciertos sectores del pensamiento liberal que a la altura del siglo XIX tampoco fueron ajenos a la explosión del "hecho nacional". La construcción de la ciudadanía y la preocupación por los derechos se mezclaban con la voluntad de pertenencia y el intento de desglosar los factores o mecanismos que regían esa identificación nacional, pero llegando a conclusiones diferentes según los autores. Así, para John Stuart Mill, la aplicación a la cuestión nacional de un principio político básico del liberalismo como que el gobierno debe responder ante los gobernados lleva a la conveniencia de que los límites estatales armonicen con los "sentimientos de nacionalidad" de sus ciudadanos (lo cual tendría un desarrollo posterior gracias al llamado "principio wilsoniano" o "principio de nacionalidad"). En cambio, para Lord Acton esto supone un peligro potencial y la mejor forma de garantizar los derechos de los ciudadanos de diferentes "nacionalidades", recientemente reconocidos por los nuevos sistemas liberales, es la convivencia en un estado multinacional con una esfera pública común y leyes propias (Özkirimli, 2000/2010, pp. 25-26).

Sin embargo, la que se considera como la gran aportación liberal para una vía de análisis del fenómeno nacional más cerca de las futuras ciencias sociales que de la reflexión sobre las "esencias patrias" fue la conferencia impartida en la Sorbona el 11 de marzo de 1882 por Ernest Renan, un académico y escritor bretón de formación filosófica y filológica. Su título era “Qu'est-ce qu'une nation?" y en ella se desmarcaba de la raza y otros rasgos "objetivos" para la definición de las naciones, reconocía su relativa novedad en la historia (aunque él la cifraba en la disolución del Imperio carolingio), así como la enorme importancia de lo político y su historicidad. Para su concepto de nación, Renan proponía una curiosa mezcla de ideas más bien románticas y otras potencialmente muy modernas, una hibridación entre el peso del pasado y la voluntad de los individuos formantes en el presente y de cara al futuro, insistiendo en la idea de que la convivencia nacional se renovaba permanentemente a través del "deseo de vivir juntos" que se expresa en la propia existencia social.

Tanto Fichte y Herder como Renan y su "plebiscito cotidiano" han sido considerados como los autores que cristalizaron en palabras dos concepciones diferentes de nación (una nación cultural-germánica y otra cívica-francesa), al servicio de dos nacionalismos diferentes, inmersos como estaban ellos mismos en un mundo de naciones. Ni siquiera los liberales más aparente e intencionadamente asépticos escapan totalmente del nacionalismo metodológico (véase el caso de Adam Smith y la equiparación del término naciones con el de "Estados" o "pueblos"). Por supuesto, aún menos lo hacen los numerosos intelectuales que se pusieron al servicio de la construcción de sus propias naciones. Es el caso de economistas como Friedrich List y sus ideas sobre la necesidad de acompasar nación y mercado, desarrollando una teoría económica basada en las naciones, o de historiadores como Jules Michelet, Modesto Lafuente o Heinrich von Treitschke, autor de una teoría del Estado belicoso y la adhesión patriótica como ámbito de realización del individuo.

Con todo, la abundancia de una temprana distinción en los textos académicos entre una forma política de entender la nación, supuestamente basada en los derechos, la voluntad y la creencia subjetiva, y otra culturalista, propia de los autores anteriores, basada en rasgos presentados como objetivos (raza, lengua, "tradiciones propias", "singularidad" y "hechos diferenciales", etc.) no debe conducirnos a equívocos. Además de problemática en sí (en la práctica, todos los casos tienen algo de ambas), las concepciones de la nación subyacentes a ella no dejan de ser una explicitación intelectual de filósofos e historiadores sobre una nación más celebrada y aceptada que problematizada y criticada. Su valor constituye más un prólogo que un primer capítulo a la hora de explicar los orígenes de una aproximación no nacionalista al estudio de las naciones. No obstante, aquellos que podrían haber ofrecido ese primer capítulo en tanto que son considerados clásicos y fundadores para las ciencias sociales actuales (nos referimos a Marx, Durkheim y Weber) tampoco resultan totalmente satisfactorios. ${ }^{4}$ Su producción sobre un tema que a veces es de difícil encaje en sus "grandes teorías" sobre la realidad social es muy reducida y parece que en lo que a la nación se refiere ese enfoque científico cuya fundación se les atribuye se nubla un poco, fundamentalmente como resultado de su ideología y su contexto personal. Karl Marx era un antinacionalista bastante definido de tintes internacionalistas, Émile Durkheim era un patriota francés con perspectivas humanitarias y Max Weber un convencido nacionalista alemán de rasgos culturalistas.

La visión que Marx tiene de la nación y del nacionalismo se encuadra en su análisis de la realidad social y su teoría del desarrollo histórico. A nivel teórico considera el nacionalismo como un instrumento al servicio de la burguesía. La lealtad a la nación y el patriotismo son un invento de los burgueses para vincular al 
proletariado con un Estado que les oprime. Mientras la clase social es en el pensamiento de Marx un criterio a la vez científico y práctico, y la verdadera vía para la emancipación de las masas, la nación parecería una componenda intelectual, una especie de sombra chinesca que distraería al obrero del internacionalismo solidario de clase que debe profesar. Sin embargo, en la práctica tanto Marx como Engels tuvieron con el nacionalismo más relación de lo que se deduciría de lo que escribían. A partir de 1848/1849 comenzaron a formular su apoyo a las "causas nacionales" de Hungría o Polonia, a utilizar con mayor frecuencia las categorías nacionales en sus análisis, a reconocer la "nacionalidad irlandesa" en 1872, para acabar defendiendo que cada proletariado debe enfrentarse a su correspondiente burguesía y conseguir el poder dentro de la nación, convertirse de hecho él mismo en la nación.

¿Cómo se prolongó esto en el marxismo posterior? Destacamos dos elementos. El primero es que, al igual que en la vida de los propios Marx y Engels, la praxis produjo realidades un tanto disfuncionales con la teoría, demostrando que el problema nacional era ineludible y mucho más importante que lo que se reconocía (dos ejemplos claros son el apoyo que la mayoría de los partidos socialistas dieron a sus respectivas "causas nacionales" cuando estalló la Primera Guerra Mundial y la colosal obra de ingeniería social que hizo la Unión de Repúblicas Socialistas Soviéticas con sus "pueblos y nacionalidades", que la retórica del proletariado no podía ocultar).

El segundo de los elementos es que dentro del propio marxismo al final la nación y el nacionalismo acabaron convirtiéndose en elementos de debate. Podemos destacar dos registros a este respecto. El primero de ellos hace referencia a las discusiones entre los líderes e intelectuales sobre si se debía aumentar la consideración de las naciones y el nacionalismo como variable explicativa de una realidad cambiante. Así, cobra mayor importancia la polémica entre Lenin y Rosa Luxemburgo sobre este tema, cuando el primero criticó duramente la subestimación que había hecho la segunda de la fuerza del nacionalismo y la identidad nacional al afirmar que "El estado nacional y el nacionalismo son estuches vacíos en los que cada época y las relaciones de clase en cada país vuelcan su contenido material particular" (Vilar, 1980, p. 178). El segundo de los registros se relaciona con algunos autores que, en respuesta a unas peculiares circunstancias de su entorno particular influidas por el problema nacional, incorporaron la nación como una variable fundamental en sus análisis. Nos referimos a una corriente más bien heterodoxa del marxismo, el llamado "austromarxismo". En él autores como Otto Bauer y Karl Renner intentaron combinar socialismo y nacionalismo en sus propuestas de convivencia y autonomía nacional, así como de elección propia de la identidad. ${ }^{5}$

La visión aparentemente antinacionalista proclamada de Marx desaparece en Durkheim, que tampoco elaboró ninguna teoría sobre el nacionalismo pero cuyas escasas reflexiones sobre el tema hay que enmarcar en sus ideas sobre el funcionamiento y la conveniencia moral del Estado, sobre la educación, la división del trabajo y la religión. Como es común en la época y comprensible para el autor en cuestión, el término patriotismo se prefiere al de nacionalismo. Para Durkheim, una nación es un grupo que es "estado y nacionalidad al mismo tiempo" (para el autor las nacionalidades son "grupos humanos unidos por una civilización común sin estar unidos por una relación política"). Él define patriotismo como "un sentimiento que une el individuo a la sociedad política en la medida en que aquellos que la forman se sienten ligados a ella por un vínculo sentimental" y afirma que la patria es el "entorno normal indispensable para la vida humana". Sin embargo, cree que tiene una fecha de caducidad en tanto que vaticina que el "patriotismo mundial", entendido como universalismo humanitario, acabará por eclipsarlo según avance la civilización (Guibernau, 1996, pp. 37-38).

Por último, resta considerar a Max Weber, inspirador de muchos de los grandes estudios sociológicos y politológicos que son referencia en la actualidad pero que en esta cuestión exhibía un fuerte nacionalismo alemán. Sin embargo, Weber es el que mejor define los conceptos al separar la nación del Estado y estudiar la relación entre los grupos étnicos, el Estado y los individuos. Maneja la idea de que el vínculo entre los individuos, los grupos y las comunidades políticas debe analizarse en términos de "creencia" o "sentimiento" (y por lo tanto, introduce un factor de subjetivismo en la definición). La relación entre el Estado y la nación se realiza a través de su conceptualización del "poder": "el Estado nacional es la organización de poder temporal de la nación". Sea real o deseado, las comunidades con un pathos específico constituidas en naciones tienden a relacionarse con estructuras estatales. Según Weber, para entender las naciones es necesario conocer sus intereses de prestigio, su "misión nacional" y el sentimiento de solidaridad que une a sus miembros. Con la "Gran Guerra" se acentúa el énfasis de Weber en la realidad de las naciones y las diferencias de poder entre ellas, la recurrencia a la ra- 
zón de Estado y a la competencia y el enfrentamiento. Quizás por su nacionalismo alemán, Weber le prestó más atención a la nación que los otros autores y de su pensamiento serán rescatables algunos elementos como su aportación al ámbito del análisis político (Guibernau, 1996, pp. 40-48).

Habría que esperar al final de la Primera Guerra Mundial y a las atrocidades que se cometieron durante el periodo que Hobsbawm califica de "apogeo del nacionalismo" (1918-1950) para que algunos historiadores y científicos sociales plantearan decididamente el nacionalismo como objeto de estudio académico. ${ }^{6}$ Como indica Özkirimli (2000/2010, pp. 31-32), no estaban exentos de valoraciones morales y no problematizaban tanto la nación como el nacionalismo, pero desde luego no podemos ignorar el salto cualitativo que se produjo en la instalación de una voluntad de liberarse de prejuicios e intentar no quedar atrapados por un objeto de investigación tan proclive a ello (peligro que, incluso en el presente, no ha desaparecido). Estos primeros grandes estudios específicos incidían sobre todo en la cuestión de los orígenes y desarrollo del nacionalismo, especialmente como "ideología" o como movimiento sociopolítico.

La nueva generación de autores mostraría tres rasgos que condicionarían el debate académico hasta la actualidad. En primer lugar, presentaban un abrumador predominio del inglés como lengua comunicativa, aunque muchos tenían como lengua materna algún otro idioma germánico. En segundo lugar, gran parte eran de origen centroeuropeo y/o judío. En tercer lugar, sus aportaciones apuntaron hacia la consolidación de una perspectiva decididamente constructivista de las naciones (nation-building theories), esta vez sí, con la firme voluntad por parte de la mayoría de sus miembros de observar un fenómeno desde fuera y no tanto de racionalizar una realidad nacional aceptada y consentida. ${ }^{7}$

Así, en 1931 el historiador norteamericano Carlton Hayes, que fue embajador en la España de la Segunda República, publicó el libro The Historical Evolution of Nationalism, en el que lo presentaba como un cuerpo de doctrina, una filosofía política dirigida a amplificar artificialmente el tribalismo primitivo cuyo primer hito lo fijaban el siglo XVIII y el jacobinismo. La última versión de esa ideología sería el fascismo que le tocó vivir. También hizo énfasis en los aspectos ideológicos pero con más influencia aún Hans Kohn, quien en plena guerra mundial publicó The Idea of Nationalism: $A$ Study in Its Origins and Background (1944). Al contrario que Hayes, Kohn veía un lado positivo al naciona- lismo y lo desvinculaba de una nómina concreta de pensadores, asociándolo a las historias nacionales. Kohn abogó por una distinción que unía indirectamente naciones y nacionalismos: él hablaba de "nacionalismo occidental", racional, liberal-democrático (como el de Estados Unidos o el de Francia) y de "nacionalismo oriental" orgánico, imperial-racista (como el de la Alemania nazi). En realidad, lo que hizo Kohn fue popularizar esa diferenciación entre nación política y nación cultural que mencionamos al principio y que se remonta a Meinecke.

Hijas de su tiempo, estas primeras interpretaciones eran esencialmente político-ideológicas y venían motivadas por la voluntad de comprender una realidad dramática en la que el nacionalismo se revelaba cada vez más importante y peligroso (de ahí que llamaran la atención sus aspectos más radicales, como el secesionismo, su relación con el nazismo o el racismo). Sin embargo, ese mundo pareció desaparecer en 1945 y dar paso a otro nuevo que permitió apreciar que el tema iba mucho más allá del nacionalismo étnico exacerbado. Ese mismo año E.H. Carr publicó Nationalism and After donde, en palabras de Breuilly, "expresaba la sensación de que el asunto era ya materia de la historia" (Breuilly, 2008, p. 17). Justo en el momento en el que se daban las condiciones para la apertura de un debate académico amplio y libre de las enormes presiones de los años anteriores, el interés de los historiadores giró hacia las estructuras sociales y económicas, aunque otros científicos sociales tomaron el testigo de la vanguardia y abrieron una nueva etapa seminal para los estudios actuales. Además, los marcos y lenguajes nacionales persistieron, el constructivismo sobrevivió y el nacionalismo no desapareció. Pero lo más importante de todo es que los cimientos del debate académico tal y como lo conocemos hoy en día ya estaban puestos.

\section{LA CONSOLIDACIÓN DEL DEBATE ACADÉMICO DESDE MEDIADOS DEL SIGLO XX}

La experiencia de las guerras mundiales y los procesos de descolonización, presentados como historias de "liberación nacional", tuvieron una enorme influencia en el rumbo que tomó el debate en sus años de maduración. En las dos décadas posteriores a la 2a Guerra Mundial los historiadores participantes fueron escasos, interesada como estaba la Academia más por otros temas como el Estado, las clases sociales, la movilización colectiva o los orígenes del desarrollo económico. Sin embargo, esto no significó una paralización de los estudios sobre nación y nacionalismo. 
Los años 50 y 60 supusieron la incorporación de las teorías de la modernización y del funcionalismo americano, que contribuirían a asentar el principio del carácter "moderno" de los fenómenos nacionales como punto de discusión fundamental del debate clásico.

En esta época se publicaron algunas obras clave que serían referencia en el momento en que, con el giro postmoderno y la crisis de la historiografía, el interés por el tema se recuperará con fuerza inusitada, para adquirir carácter de centralidad en el seno de la historiografía y las ciencias sociales. La primera de esas obras fue Nationalism and Social Communication: An Inquiry into the Foundations of Nationality (1953), de Karl Deutsch. Este checo germano-parlante utilizó el enfoque de la comunicación social para concluir que la emergencia de las naciones se produjo en el momento en el que la producción, transmisión y almacenamiento de la información se tradujo en participación política, movilización social, urbanización y alfabetización, proceso que él localizaba en el mundo occidental a partir del siglo XVIII.

Sin embargo, más influyente aún en los autores posteriores sería la obra que publicó un historiador británico conservador, Elie Kedourie, en el año 1960 bajo el título Nationalism. Este libro acabaría por afirmar una posición de fortísimo ascendiente académico: el llamado "modernismo" por su defensa de la asociación entre orígenes de las naciones y procesos de modernización. Kedourie presentaba un enfoque más ideológico que sociológico y veía el nacionalismo como un producto de la llustración y el Romanticismo. ${ }^{8}$ Kedourie definió las naciones como creaciones artificiales, resultado de la acción de intelectuales al servicio del Estado o excluidos del poder, que inoculan sus ideas "como una ideología que se expande cual enfermedad" (Smith, 2009, pp. 4-6; Breuilly, 2008, p. 4). En los años siguientes, las ideas del británico acabaron por consolidar el modernismo como una ortodoxia y pese a algunas visiones críticas que no estaban de acuerdo con algunos de sus postulados expresadas en los primeros trabajos de Walker Connor o Anthony Smith ${ }^{9}$, el modernismo clásico supuso la fuente de influencia principal en el momento en que el debate académico dio el siguiente paso a nivel de producción tanto teórica como historiográfica.

Aparte de esas primeras críticas, los años setenta vieron algunas aportaciones del postmarxismo basadas en factores económicos. Se trata de los libros ya clásicos de Michael Hechter Internal Colonialism: the Celtic Fringe in British National Development, 15361966 (1975) y de Tom Nairn, The Break-up of Britain:
Crisis and Neonationalism (1977). El primero aplicó la idea de colonialismo interno a la lectura de las diferencias regionales en un sentido de centro-periferia (por ejemplo, entre Inglaterra y Gales) para explicar el surgimiento de identidades nacionales alternativas, admitiendo el papel de las solidaridades culturales. El segundo, sirviéndose del caso británico, relaciona el imperialismo y el desarrollo desigual del capitalismo, estableciendo uno de los motores fundamentales para el surgimiento de resistencia nacional (mediando el Romanticismo y el populismo). Ambos autores tienen gran influencia en las interpretaciones actuales de las naciones y el nacionalismo en clave materialista. ${ }^{10}$

Por último, en los setenta se produjo la publicación de dos obras realizadas a partir de estudios de caso (Alemania y Francia) que aportaron sistematizaciones que serían fundamentales para los estudiosos sobre nación y nacionalismo. La primera es la "nacionalización de las masas", de George Mosse (1975), donde se abordaba la nación como una construcción social y no solo intelectual desde la cultura política y su relación con el Estado y la sociedad civil. La segunda es la obra de Eugen Weber From Peasants into Frenchmen (1976), que sirvió de modelo para el estudio de la construcción efectiva de los Estados-nación y la introducción de la nación en la vida de la mayoría de población de un territorio. Su influencia en la historiografía española sería enorme.

La década de los ochenta, con sus nuevos contextos tanto generales como en el mundo intelectual, verá la aparición de una serie de obras que introducirán algunas novedades en el paradigma modernista y constituirán los clásicos sobre los que se apoya cualquier estudioso actual, los hitos de la madurez, los libros de referencia que atraerán al tema a numerosos historiadores y, sobre todo, científicos sociales. En 1982 John Breuilly publicó Nationalism and the State, en el que definía al nacionalismo como una "forma de política" y estudiaba los diversos casos en los que el nacionalismo se enfrenta al Estado. Así, el autor sostiene que la mejor forma de entenderlo es a través de su relación con las estructuras políticas con las que se relaciona, en progresivo proceso de modernización y burocratización. Por lo tanto, un enfoque exclusivamente cultural resulta incompleto. Así, conflicto político y exclusión del poder se concretan y aparecen más claros en la ecuación que explica el surgimiento del nacionalismo. ${ }^{11} \mathrm{El}$ valor de la aportación de Breuilly, que pasa de lo ideológico a lo político, no obstante, se ve disminuido por la ausencia de un mayor tratamiento precisamente de los llamados "nacionalismos de Esta- 
do". Con todo, el paradigma modernista se fortaleció con ese enfoque estatalista.

Muy diferente al libro de Breuilly fue el que publicó el mismo año John Armstrong, que se puede inscribir en la corriente crítica al entendimiento de la nación exclusivamente a través del nacionalismo. Confuso para unos y criticado por otros, Nations before $\mathrm{Na}$ tionalism es un estudio sobre la emergencia de las naciones a partir de realidades premodernas. Para el autor, lo importante son los procesos de identificación étnica, la construcción de fronteras cognitivas (culturales, lingüísticas, geográficas...) y la modulación que los grupos humanos imprimen a sus realidades simbólicas particulares. Para Armstrong estos procesos ocurrieron en algunos lugares muchos siglos antes de la "modernidad" contemporánea (por ejemplo en la frontera entre cristianos y musulmanes en la España medieval). Así, algunas naciones serían realmente antiguas, el resultado de un proceso de evolución desde ciertas realidades étnicas que solo puede entenderse como longue durée, proceso del cual la modernidad es una parte. El hilo conductor entre una realidad y otra sería el complejo "mito-símbolo", la conexión entre vivos y muertos a través de la categorización colectiva de la realidad pasada y presente que permite una cultura propia. Con frecuencia ignorado, y muchas veces criticado por tratar los grupos étnicos más que las naciones, el libro de Armstrong no fue influyente en el momento, pero sí proporcionó ideas importantes a otros autores posteriores como Anthony Smith, tales como la aplicación del concepto de "mito-motor" (mythomoteur), entendido como el mito o conjunto de mitos que proporcionan a un grupo étnico (y por derivación a una nación) una misión histórica o, si se quiere, un sentido en el mundo. ${ }^{12}$

Muchísimo más influyente que Breuilly a la hora de contribuir a convertir el modernismo en un paradigma hegemónico en la historiografía y las ciencias sociales ha sido la obra de Ernest Gellner, filósofo y antropólogo nacido en Praga que ya perfiló su teoría sobre naciones y nacionalismos en un capítulo de su Thought and Change (1964) pero que apenas tuvo impacto. No así cuando lo sistematizó, lo enriqueció y lo publicó en un contexto más favorable bajo el título Nations and Nationalism (1983). Gellner define el nacionalismo como un "principio político que sostiene que debe haber congruencia entre la unidad nacional y la política". Según su teoría, el surgimiento de las naciones y de los nacionalismos en base a este principio se explica en el marco de la transición de la sociedad agraria a la sociedad industrial. Lo que él llamó "industrialismo", muy criticado posteriormente, intentaba resumir las profundas transformaciones sociales, económicas y culturales que conllevaba este proceso. Así, sobre la base de estas nuevas condiciones, en una sociedad mucho más móvil, comunicativa y conflictiva, la identidad nacional vendría a sustituir vacíos dejados por el cambio estructural. Las "culturas superiores" la utilizarían para hegemonizar sus sociedades en un sentido nacional o podrían desarrollar nacionalismos cuando se hallaran en situación de desigualdad en la veloz dinámica del desarrollo económico. La conclusión es que "el nacionalismo engendra las naciones, y no a la inversa" (Gellner, 1983/2008, p. 136).

Más o menos matizado en obras posteriores, ${ }^{13} \mathrm{cri}$ ticado por su excesivo funcionalismo o abstracción, Gellner se convirtió en un estandarte fundamental del modernismo $y$, en virtud de su hegemonía, en una autoridad cuando se debatía el tema en cualquier ambiente más o menos académico. ${ }^{14} \mathrm{El}$ modernismo acabó por apuntalarse con la publicación en ese mismo año de 1983 de dos obras universalmente citadas y cuyas ideas-fuerza, incluidas en sus títulos, continúan vivas hoy en las visiones de muchos historiadores y científicos sociales. Se trata del libro de Benedict Anderson Imagined Communities: Reflections on the Origin and Spread of Nationalism y el editado por Eric Hobsbawm y Terence Ranger bajo el título The Invention of Tradition. En este último, las diferentes contribuciones señalaban cómo la mitificación y el ritual podían crear sensaciones de antigüedad que apuntalaran distintas realidades sociales, políticas o culturales al presentarlas como "tradiciones", cuando en realidad habían tenido una fabricación bastante reciente. El concepto de "invención de la tradición" se popularizó y tuvo múltiples aplicaciones, una de ellas dirigida a expresar el carácter reciente de las naciones.

Por su parte, el libro de Anderson, menos abstracto y más empírico que el de Gellner, más cultural-antropológico que social-economicista, tuvo un éxito parecido, pero su idea de "comunidad imaginada" parece haber calado más profundamente, incluso entre los historiadores no especializados. ${ }^{15}$ Dos de las aportaciones más significativas del autor son, por un lado, la explicación del origen de las conciencias nacionales, de la posibilidad de imaginar la nación; y por otro lado, la expansión de la nación y el nacionalismo como aspectos centrales de la realidad humana. Para Anderson, la imaginación de la nación fue posible por la conjunción de dos elementos. En primer lugar, el derrumbamiento de tres concepciones culturales tra- 
dicionales: el acceso privilegiado a la escritura portadora de la verdad ontológica, las ideas de jerarquización y verticalidad social sancionadas por la divinidad y la concepción tradicional de la temporalidad que unía cosmología e historia, orígenes del mundo con orígenes del hombre. En segundo lugar, una serie de cambios estructurales y descubrimientos en las realidades materiales y cognitivas del hombre, como la imprenta (Anderson, 1983/2006, p. 26). Ambas cosas producidas por la modernización, conducen a la segunda aportación, que intenta explicar por qué se produjo el paso hacia esa nueva imaginación sociopolítica. La respuesta de Anderson es el desarrollo de lo que él llama "capitalismo de imprenta" (print capitalism), que en conjunción con las condiciones anteriores y el desarrollo estandarizado de las lenguas vernáculas, permitiría, llegadas las convulsiones políticas que se dieron en el hemisferio occidental entre 1776 y $1838^{16}$, el proceso de desarrollo de las naciones en sentido moderno, aunque no de forma simultánea, ni siguiendo exactamente los mismos procesos, ni presentando los mismos resultados, ni, por supuesto, habiendo ninguna fatalidad o predestinación en el desarrollo de una nación determinada por la existencia de una lengua impresa previa. ${ }^{17}$

A partir de 1983, Gellner, Anderson y Hobsbawm quedarían como la gran tríada de referencia en naciones y nacionalismos, dominante en la literatura y el medio público, y sus ideas proyectarían un fuerte ascendiente sobre la mayoría de las obras modernistas posteriores. Sin embargo, durante esa década se produjeron otras aportaciones originales, algunas de ellas articuladoras ya de una crítica sistemática al modernismo, otras contribuyentes a su enriquecimiento desde perspectivas menos teóricas. En 1985 se publicó Social preconditions of national revival in Europe, una traducción de una obra de otro checo, Miroslav Hroch, escrita originalmente en alemán (Die Vorkämpfer der nationalen Bewegungen bei den kleinen Völkern Europas) y que databa de 1968. Entonces pasó bastante desapercibida para el debate fuertemente centrado en el mundo anglosajón, pero hoy Hroch es reconocido como un verdadero pionero e inspirador de muchos modernistas. El objetivo del autor era estudiar el polvorín de nacionalidades que era la Europa central y oriental en la época contemporánea a través de un análisis empírico bastante solvente. Sus conclusiones, en primer lugar, asociaban surgimiento de nacionalismo a las tensiones de la modernización (lo cual lleva a una idea de desarrollo desigual de la conciencia nacional a nivel territorial y social). En segundo lugar, proponían un modelo para la "creación de naciones" en tres fases. La fase A sería la imaginación de la nación por parte de un grupo relativamente pequeño de intelectuales, normalmente expresado por fenómenos folclóricos o de "renacimiento" cultural. La fase B consistiría en la formación de movimientos políticos y sociales en torno a esa idea. La fase $C$ sería el éxito a la hora de socializar a las masas en esa idea nacional, consolidando así la existencia de la nación. Aunque el modelo de Hroch es muy útil para el análisis de los "nacionalismos sin Estado", no se adapta tan bien a otras historias de construcción nacional. Sin embargo, contribuyó enormemente a la concepción modernista de la nación como algo "artificial".

Aparte del robustecimiento del modernismo, estos años vieron la definición más clara de posturas alternativas insatisfechas con sus postulados, muy inspiradas por la antropología, la etnología y la creciente historia cultural. Es el caso de la obra de John Hutchinson The Dynamics of Cultural Nationalism: the Gaelic Revival and the Creation of the Irish Nation State (1987). A la hora de la analizar las formas políticas y sobre todo culturales del nacionalismo irlandés, Hutchinson se dio cuenta de que algunos de sus rasgos se fundamentaban en realidades no exclusivamente modernas y que era necesario un enfoque a largo plazo para comprenderlas. En esa misma línea se halla el libro de Anthony Smith The Ethnic Origins of Nations, publicado ese mismo año, donde ya sostenía claramente que algunas naciones no se entienden en el estrecho marco de la modernidad y que es necesario remontarse a sus orígenes étnicos premodernos.

Sin embargo, el modernismo no se derrumbó sino que se reafirmó en sus postulados, se fortaleció y acabó de socializarse en la comunidad académica de la mano de un nuevo superventas resultado de la sistematización por escrito de unas famosas conferencias (Wiles Lectures) que impartió Eric Hobsbawm en la Queen's University de Belfast en 1985 . El resultado fue un libro publicado en 1990 bajo el título Nations and Nationalism Since 1780: Programme, Myth, Reality. En él Hobsbawm definía su posición de modernista radical. Las naciones eran "artefactos culturales" fabricados por las élites gobernantes o aspirantes al poder para movilizar a las masas en su favor (Hobsbawm, 1991, pp. 17-19). Su asociación con la modernidad y, en origen, con el liberalismo, es para Hobsbawm algo básico. La nación parece el instrumento revolucionario que permite la quiebra de los universos de Antiguo Régimen y la construcción del Estado liberal. Todo lo anterior a este proceso es catalogado por el autor como "protonacionalismo". Con la cristalización de los 
Estados nacionales y el giro hacia el conservadurismo, ciertas élites excluidas realizan apropiaciones y lecturas independientes del principio de nacionalidad y crean sus nacionalismos sin Estado, enfrentados a los correspondientes Estados-nación.

Hobsbawm tuvo el acierto de dotar de una historicidad clara y definida al proceso de transformación tanto de contenidos semánticos como de utilizaciones de la nación en tanto que invención cultural, dedicando un capítulo a cada fase. 1) Protonacionalismo popular antes de la modernidad; 2) en su nacimiento: nación como progreso, más bien cívica; 3 ) desde mediados del siglo XIX, transformación conservadora o reaccionaria, hacia rasgos culturalistas o lingüísticos; 4) 1918-1950: apogeo del nacionalismo, paroxismo y exacerbación (ejemplo del fascismo); 5) desde 1950, pierde importancia con la excepción de su "asociación con la izquierda" en los procesos de descolonización; finalmente, en las postrimerías del siglo XX ha dejado de ser una "fuerza histórica" significativa. Hobsbawm concluyó que "los cambios habidos en 1989 y después no se debieron en esencia a tensiones nacionales" (1991, p. 177) y que de cara al siglo XXI "nación y nacionalismo ya no son términos apropiados para describir, y mucho menos para analizar, las entidades políticas que se califican de tales, o siquiera los sentimientos que en otro tiempo se describían con ellos" (1991, p. 202).

Pese a que los hechos acaecidos desde entonces han puesto en problemas las afirmaciones de Hobsbawm, hoy en día es uno de los textos más recomendados para introducirse en el tema y conforma el remache final de un doble proceso: la constitución del estudio sobre naciones y nacionalismo como uno de los temas centrales en el debate académico y la consolidación del modernismo como un paradigma pujante y dominante en ese debate. De ese momento a la situación actual solo resta señalar la gran explosión de obras y aportaciones de los años noventa, espoleada por un contexto favorable dentro y fuera de la Academia, y que en cierto modo perdura hasta la actualidad.

Puede que el último gran hito de la cadena anterior pero a la vez la primera gran obra de esta nueva generación de estudios sobre nacionalismo sea el de Liah Greenfeld, socióloga y antropóloga nacida en Rusia pero formada en Israel. Su libro Nationalism: Five Roads to Modernity aporta cinco excelentes estudios de caso sobre la construcción nacional de Inglaterra, Francia, Alemania, Rusia y los Estados Unidos desde la idea de que el nacionalismo es fundamental para conocer el mundo actual. Además, realiza aportacio- nes teóricas sobre los orígenes de la nación y el nacionalismo (Greenfeld, 1993, pp. 3-26). Para la autora, la extensión de la idea nacional se produjo a partir del siglo XVIII, donde la palabra "extensión" tiene su significado más puramente difusionista. La nación se originó cuando el significante natio sufrió un cambio semántico y comenzó a asimilarse con "pueblo", primero con una connotación de soberanía y después con otra de singularidad. La forma de entender la expresión del concepto "pueblo" a través de la nación explica las diferencias entre nacionalismos cívicos y étnicos, pero lo importante es la creación de ese nuevo orden simbólico.

Este proceso tuvo lugar en la Inglaterra del siglo XVI, que es para Greenfeld la primera nación del mundo y la exportadora de la idea al resto de los países (Greenfeld, 1993, p. 14). Esta exportación se realiza a través de una combinación de "herencia", "influencia" y "reacción interna" en situaciones de anomia, resultado de las crisis estructurales iniciadas en la segunda mitad del XVIII, y mediante el mecanismo psicológico del ressentiment. ${ }^{18}$ Desde luego, el libro de Greenfeld no tiene el perfil divulgativo del de Hobsbawm. Además, presenta algunas exageraciones (a veces parece que la cuestión parece resumirse en algo así como "ex Britannia lux"). Su esquema difusionista y su seguridad en que no se necesitan más casos que los que ella maneja para comprender los orígenes de las naciones y los nacionalismos son aspectos bastante criticables. ${ }^{19}$

En 1995, David Miller publicó su ensayo On Nationality, donde planteaba una defensa razonable de una concepción moderada del nacionalismo. Sin embargo, la obra de ese año más influyente sería de un psicólogo social británico, Michael Billig, con el título Banal Nationalism. Por fin se abordaba sistemáticamente y con impacto en la comunidad académica dos temas un tanto olvidados por las obras anteriores y de gran importancia en la actualidad: a) la cuestión de los patriotismos estatales a nivel de identidad y de vivencia; $y$ b) las manifestaciones cotidianas del nacionalismo (everyday life experiences), que suponían una continua socialización en los valores nacionales en los que las masas eran partícipes y que en muchos casos no se percibían como nacionalismo explícito (quizá el ejemplo más gráfico y extendido sean las competiciones deportivas).

Dos años después, en 1997, se publicaron dos aportaciones que eran síntoma de la extraordinaria apertura de panorama y diferenciación de posiciones que el debate estaba alcanzando. La de Craig Calhoun era un ensayo de síntesis con algunos elementos de compromiso como la importancia que le concedía a las 
cuestiones étnicas y a los vínculos de parentesco, a la par que ahondaba en su propuesta del nacionalismo como "formación discursiva", desarrollada posteriormente, por la que las naciones no podrían existir más allá del discurso nacionalista que les da vida. Por su parte, Adrian Hastings, desde el pensamiento cristiano, realiza una dura crítica al modernismo y más concretamente a Hobsbawm en The Construction of Nationhood: Ethnicity, Religion and Nationalism, también originado a partir de unas Wiles Lectures. ${ }^{20} \mathrm{Al}$ igual que Greenfeld, Hastings cree que la clave de todo está en Inglaterra, cuyo carácter nacional retrasa a la Edad Media y en la puesta por escrito de la lengua vernácula, proceso en el que la Biblia juega un papel fundamental. Para Hastings, existen naciones y nacionalismos medievales que no son muy diferentes a sus versiones modernas (algo que se le ha criticado mucho) y aspectos como la etnicidad y la religión (más bien la imaginación religiosa) son el núcleo para la conformación de naciones, pese al fuerte rechazo que producen en los modernistas (Hastings, 2000, pp. 11-51). El radicalismo antimodernista de Hastings le ha costado el ostracismo intelectual hasta la actualidad y un buen número de críticas bien fundamentadas. No obstante, es un signo de la insatisfacción de muchos autores con el modernismo, especialmente entre los historiadores dedicados a la Edad Media y a la Edad Moderna que quieren entrar en el debate con sus argumentos de continuidad pero que se ven bloqueados por la insistencia en la ruptura de algunos contemporaneístas.

En las últimas dos décadas del siglo XX, la reflexión teórica sobre los fenómenos nacionales fue hegemonizada por obras publicadas en inglés. Sin embargo, la genealogía de esta hegemonía debe matizarse. Muchos de los autores que escriben en inglés en realidad no son anglosajones, sino que tenían otras procedencias, como Deutsch, Mosse o el propio Hroch, que ganó predicamento cuando fue traducido. Además, en el mundo occidental existen otras tradiciones que también han intentado aportar al debate, si bien con menor impacto. Academias como la española o la italiana no han desarrollado síntesis y aportaciones teóricas propias hasta entrados los años 90, por lo que su dependencia de Anderson, Gellner y Hobsbawm, entre otros, es mayor. ${ }^{21}$ Una situación un poco más independiente es la francesa, con el concepto de "lugares de memoria" habiendo cosechado bastantes éxitos, aunque no sin críticas por la incapacidad, comenzando por Pierre Nora, su formulador, de despegarse de una cierta nostalgia exaltadora de la nación. ${ }^{22}$ Aunque también con retraso, a la par que el modernismo an- glosajón se extendía encontramos en francés ensayos de reflexión (Maalouf, 1998) y libros de síntesis (Hermet, 1996; Thiesse, 1999) con una cierta originalidad.

Sin embargo, parece claro que el único ámbito académico occidental con una tradición propia lo suficientemente potente como para plantear una resistencia a la hegemonía anglosajona es el germanoparlante, del cual de hecho proceden en última instancia muchas de las ideas (y de los autores) que han alimentado las academias anglófonas, incluso ya desde el siglo XIX: el mencionado Friedrich Meinecke y la distinción entre Kulturnation (nación cultural) y Staatsnation (nación política); Ferdinand Tönnies y los conceptos de Gemeinschaft (comunidad) y Gesellschaft (sociedad), etc. Como señala Dieter Langewiesche (2012, pp. 42-43), mucho antes de que se popularizara el carácter moderno y construido de las naciones en los años 80-90, ya se habían publicado varias obras en alemán sobre teoría del nacionalismo en esta línea, como Ethnos und Demos (1965) de Emerich Francis, Nationalismus (1964) de Eugen Lemberg o Die moderne Nation (1931) de Heinz Ziegler. Además, en los noventa también encontramos alguna síntesis alemana de bastante difusión, como la de Schulze (1994), traducida a once idiomas, incluido el inglés.

\section{CONSIDERACIONES FINALES}

Cuando terminó el siglo XX, el balance era sencillo de trazar: un debate rico y múltiple, cada vez más amplio y cargado con más matices, en el que participan tanto científicos sociales como historiadores, debate cada vez más implicado en la investigación empírica y la aplicación historiográfica de las perspectivas teóricas; un paradigma, el modernista, maduro y solvente para muchos, bien definido y dominante; y unas críticas cada vez más fuertes y coherentes, no abordadas en este texto pero que no consiguen desplazarlo del todo de su centralidad, ni tampoco iniciar un proceso de convergencia entre teorías.

En la actualidad, el debate sobre la nación es más complejo y polifónico que en los años ochenta-noventa. La discusión sobre el origen de las naciones se ha venido complementando por nuevas corrientes más sensibles al postmodernismo, el pensamiento postcolonial, el feminismo, etc., las cuales defienden que la obsesión por datar desde cuándo podemos hablar de naciones y nacionalismo oculta otras cosas igualmente interesantes (como explicar el funcionamiento del vínculo nacional o su interacción con otras realidades). Anunciadas por algunas obras publicadas ya en la época de los noventa (como la de Greenfeld o la de 
Calhoun), hoy la situación se caracteriza a la vez por la apertura y la incertidumbre sobre si estas nuevas perspectivas acabarán consolidándose.

Esto es así hasta tal punto que algunos autores defienden que hemos entrado, de la mano de lo publicado a finales de los ochenta y en los noventa, en una nueva fase de producción académica al respecto, diferente a la que comenzó a mediados del siglo XX Özkirimli, 2000/2010, p. 167). El análisis de estas nuevas tendencias supera los límites de este trabajo, pues su objetivo ha sido trazar el recorrido que ha llevado a ellas, trufado de obras que siguen siendo una referencia fundamental para la mayoría de los estudiosos y que son imprescindibles para entender nuestra situación actual en el debate académico.

\section{NOTAS}

1 Aunque no hay tantos artículos de introducción a la historiografía sobre el nacionalismo, sí tenemos buenas monografías, más extensas y detalladas, diseñadas para este mismo fin. Las más populares son las obras de A. Smith (en especial la de 1998) y Özkiriml (2000/2010). También conviene destacar un enorme esfuerzo por la elaboración de enciclopedias y diccionarios, como el editado por J. Breuilly (2013), el de Herb y Kaplan (2008) o el de Delanty y Kumar (2006). Hay otros recorridos y reflexiones teóricas interesantes en James (1996), Real Alcalá (2007), Harris (2012) y Coackley (2012) y una recopilación de referencia en Eley y Suny (1996).

2 Nuestro recorrido acaba en el siglo $X X$. Sin embargo, los estudios actualmente siguen evolucionando, bien como continuación de lo ya sostenido, bien como reacción o proposición de alternativas. Para un tratamiento de estas nuevas corrientes, véase Özkirimli (2005 y 2000/2010, pp. 169-219).

3 Entendemos por "nacionalismo metodológico" la naturalización y normalización incuestionada de la nación como marco cognitivo del trabajo intelectual y la consideración de la realidad contemporánea como un mundo de naciones en el cual estas son sujetos colectivos agentes del cambio histórico, indiscutibles en su legitimidad y su cohesión como tales.

4 Sobre el tratamiento del tema que hicieron Marx, Durkheim y Weber, así como de los orígenes y primeros momentos del debate académico, seguimos a Guibernau (1996, pp. 15-55), Breuilly (2013 y 2008, pp. 15-20) y Özkirimli (2000/2010, pp. 9-39). También véase Lawrence (2005, pp. 17-58).

5 Sobre la tradición marxista y los estudios sobre nacionalismo véase Day y Thompson (2004, pp. 18-40).
6 Una ampliación de las producciones de esta época puede seguirse en Lawrence (2005, pp. 59-106).

7 Utilizo aquí el término constructivismo en su sentido amplio, es decir, el de que las naciones no son productos naturales, esenciales e históricamente inalterables, sino resultado de un "proceso de construcción nacional". Algunas de las últimas corrientes de análisis del fenómeno nacional hablan de constructivismo en un sentido más específico, relacionado con el postmodernismo, la lingüística y el análisis discursivo.

8 En esta línea más ideológica también está Minogue (1967).

9 Algunos de los primeros ensayos de Walker Connor en los años setenta están recogidos en Connor (1994). El primer gran libro de Anthony Smith en este sentido fue Theories of Nationalism (1971). Desde las posiciones de un historiador liberal, hay que destacar la aportación empírica con un enfoque muy bien definido en la diferenciación de Estado, nación y nacionalismo que realizó Hugh Seton-Watson (1977). Sin embargo, su libro quedaría eclipsado por las obras de principios de la década siguiente.

10 Para un desarrollo alternativo de esta vía, véase también Balibar y Wallerstein (1991).

11 "It is the shift of political conflict away from the core political community of the state and also towards sections of society hitherto excluded from political life which provides the particular conditions for nationalism to develop" (BreuiIly, 1982/1994, p. 375).

12 Si la etiquetación de los autores es ya problemática y simplificadora, entre primordialistas, perennialistas, etnosimbolistas, modernistas y postmodernistas, de una mayor a menor aceptación de la antigüedad y solidez ontológica del fenómeno nacional, Armstrong es de por sí un autor que se ha calificado tanto de perennialista como de precursor del etnosimbolismo (Özkirimli, 2000/2010, p. 204)

13 Su última obra, ya póstuma, fue una revisión en este sentido: Nationalism (1997).

14 Y su propia obra también se convirtió en objeto de estudio. Véase Hall (2000)

15 Quizás una de las razones de su popularidad sea la claridad con la que lo expresa, algo que no es muy común en la literatura: "In an anthropological spirit, then, I propose the following definition of the nation: it is an imagined political community and imagined as both inherently limited and sovereign. It is imagined because the members of even the smallest nation will ever know most of their fellow-members, meet them, or even hear of them, yet in the minds of each lives the image of their communion." Después concreta claramente los tres rasgos que completan la definición de nación: nación imaginada como ente limitado, nación imaginada como soberana, nación imaginada como comunidad (lazos horizontales entre sus miembros). En Anderson (1983/2006, pp. 5-7).

16 Anderson (1983/2006, p. 46). Quizás sería más conveniente, y así lo entiende la mayoría de la historiografía, fijar el momento revolucionario de 1848 o en todo caso toda la década de los treinta.

17 Para Anderson "el origen del nacionalismo está en el Nuevo Mundo, no en el Viejo" y el procedimiento de extensión sería a través del "pirateo" de la idea nacional y de la expansión del capitalismo impreso (Anderson, 1983/2006, p. 67, p 191).

18 Ressentiment es una palabra francesa originalmente utilizada por el filósofo 
Søren Kierkegaard, después tomada por Nietzsche, y finalmente conceptualizada por Max Scheler. Hace referencia a una mezcla de envidia, rechazo, odio y frustración, altamente invasiva sentimentalmente y que, aplicada a la identidad nacional, combina la importación con la reacción indígena al acervo nacional, resultando la versión autóctona. Greenfeld (1993, pp. 15-17) establece una analogía entre el proceso de asunción de la forma nacional de organización simbólica de la realidad y lo que Nietzsche llamó "transfiguración de los valores" (Umwertung aller Werte), una forma bastante particular de expresar la tensión modernidad/tradición que

\section{BIBLIOGRAFÍA}

Anderson, B. (1983/2006). Imagined Communities: Reflections about the Origin and Spread of Nationalism. Londres: verso.

Armstrong, J. (1982). Nations before nationalism. Chapel Hill: The University of North Carolina Press.

Balibar, É. y Wallerstein, I. M. (1991). Race, Nation, Class: Ambiguous Identities. Londres-Nueva York: Verso.

Billig, M. (1995/2009). Banal Nationalism. Londres: Sage.

Breuilly, J. (1982/1994). Nationalism and the State.Chicago: The University of Chicago Press.

Breuilly, J. (2008). Introducción. En Gellner, E. Naciones y nacionalismo. Madrid: Alianza, pp. 11-75.

Breuilly, J. (2013). Introduction: concepts, approaches, theories. En Breuilly, J. (ed.) The Oxford Handbook of the History of Nationalism. Oxford: Oxford University Press, pp. 1-18.

Calhoun, C. (1997). Nationalism. Minneapolis: University of Minnesota Press.

Carr, E. (1945). Nationalism and after. Londres: Macmillan.

Chabod, F. (1961). L'idea de nazione. Bari: Laterza.

Coackley, J. (2012). Nationalism, Ethnicity and the State: Making and Breaking $\mathrm{Na}$ tions. Los Ángeles: Sage.

Connor, W. (1994). Ethnonationalism: the Quest for Understanding. Princeton: Princeton University Press. se vivió en muchos lugares y su carácter profundo y substancial.

19 En los noventa las críticas contra el occidentalismo y el eurocentrismo metodológico ya hacía mucho que habían tomado cuerpo de la mano, entre otros, del pensamiento postcolonial, pero al parecer Greenfeld (1993, p. 23) decidió no considerarlas y usó un argumento bastante carcomido y hoy en día inaceptable: "The cases were chosen for several reasons. One was the undisputed centrality of each one of them in modern history. Between them they set the pattern followed by the rest of the planet, and have presided over its development. The transformations within

Day, G. y Thompson, A. (2004). Theorizing Nationalism. Basingstoke-Nueva York: Palgrave Macmillan.

Delanty, G. y Kumar, K. (eds.) (2006). The Sage Handbook of Nations and Nationalism. Londres: Sage.

Deutsch, K. (1953). Nationalism and Social Communication: An Inquiry into the Foundations of Nationality. Nueva York: MIT-Wiley.

Eley, G. y Suny, R. G. (eds.) (1996). Becoming National: A Reader. Nueva York: Oxford University Press.

Gellner, E. (1997). Nationalism. Nueva York: New York University Press.

Gellner, E. (1983/2008). Naciones y nacionalismo. Madrid: Alianza.

Greenfeld, L. (1993). Nationalism: Five Roads to Modernity. Cambridge (Mass.): Harvard University Press.

Guibernau, M. (1996). Los nacionalismos. Barcelona: Ariel.

Hall, J. A. (ed.) (2000). Estado y nación: Ernest Gellner y la teoría del nacionalismo. Madrid: Cambridge University Press.

Harris, E. (2012). Nationalism: Theories and Cases. Edimburgo: Edinburgh University Press.

Hastings, A. (2000). La construcción de las nacionalidades: etnicidad, religión y nacionalismo. Madrid: Cambridge UniversityPress.

Hayes, C. (1931). The Historical Evolution of Modern Nationalism. Nueva York: Richard R. Smith. them, which are the subject of this book, have repercussions far beyond their borders. In these five societies were shaped the destinies of our world."

20 "Solo se avanzará en la comprensión de las naciones y el nacionalismo cuando se abandone la idea de que existe un vínculo indisociable entre estos y la modernización" (Hastings, 2000, p. 21).

21 Por supuesto, con excepciones como Chabod (1961) o Recalde (1982).

22 Dentro de la gran obra colectiva dirigida por el historiador francés, la nación se trata explícitamente en Nora (1986-1993).

Hechter, M. (1975). Internal Colonialism: The Celtic Fringe in British National Development, 1536-1966. Berkeley: University of California Press.

Hechter, M. (2000). Containing nationalism. Oxford: Oxford University Press.

Herb, G. H. y Kaplan, D. H. (eds.) (2008). Nations and Nationalism: A Global Historical Overview. Santa Barbara: ABC-Clio.

Hermet, G. (1996). Histoire des nations et du nationalisme en Europe. París: Éditions du Seuil.

Hobsbawm, E. (1991). Naciones y nacionalismo desde 1780. Barcelona: Crítica.

Hobsbawm, E. y Ranger, T. (eds.) (1983). The Invention of Tradition. Cambridge: Cambridge University Press.

Hroch, M. (1968/1985). Social Preconditions of National Revival in Europe: A Comparative Analysis of the Social Composition of Patriotic Groups among the Smaller European Nations.Cambridge: Cambridge University Press.

Hutchinson, J. (1987). The Dynamics of Cultural Nationalism: the Gaelic Revival and the Creation of the Irish Nation State. Londres: Allen \& Unwin.

James, P. (1996). Nation Formation.Towards a Theory of Social Community. Londres: Sage.

Kedourie, E. (1960). Nationalism. Londres: Hutchinson.

Kohn, H. (1944). The Idea of Nationalism: A Study in Its Origins and Background. Nueva York: Macmillan. 
Langewiesche, D. (2012). La época del estado-nación en Europa. Valencia: Publicacions de la Universitat de València.

Lawrence, P. (2005). Nationalism. History and Theory. Harlow: Pearson.

Maalouf, A. (1998). Les identités meurtrières. París: Grasset.

Miller, D. (1997). On Nationality. Oxford: Clarendon Press.

Minogue, K. (1967). Nationalism. Londres: Methuen.

Mosse, G. L. (1975). The Nationalization of the Masses: Political Symbolism and Mass Movements in Germany from the Napoleonic Wars through the Third Reich. Nueva York: H. Fertig.

Nairn, T. (1977). The Break-up of Britain: Crisis and Neonationalism, Londres: New Left Books.
Nora, P. (1986-1993). (dir.) Les lieux de mémoires (vol. II: La Nation). París: Gallimard.

Özkirimli, U. (2005). Contemporary Debates on Nationalism: A Critical Engagement. Basingstoke: Palgrave Macmillan.

Özkirimli, U. (2000/2010). Theories of Nationalism.A Critical Introduction. Basingstoke: Palgrave Macmillan.

Real Alcalá, J. A. del (2007). Nacionalismo e identidades colectivas: la disputa de los intelectuales (1762-1936). Madrid-Jaén: Dykinson-Universidad de Jaén.

Recalde, J. R. (1982). La construcción de naciones. Madrid: Siglo Veintiuno.

Schulze, H. (1994). Staat und Nation in der europäischen Geschichte. Munich: C. H. Beck.
Seton-Watson, H. (1977). Nations and States: An Enquiry into the Origins of $\mathrm{Na}$ tions and the Politics of Nationalism. Londres: Methuen.

Smith, A. (1971). Theories of Nationalism. Londres: Duckworth.

Smith, A. (1991). The Ethnic Origins of $\mathrm{Na}$ tions. Oxford-Malden: Willey-Blackwell.

Smith, A. (1998). Nationalism and Modernism. Londres: Routledge.

Smith, A. (2009). Ethno-symbolism and Nationalism. Abingdon: Routledge.

Thiesse, A. M. (1999). La création des identités nationales. Europe XVIII'-XIX ${ }^{e}$ siécle. París: Éditions du Seuil.

Vilar, P. (1980). Iniciación al vocabulario del análisis histórico. Barcelona: Crítica. 